\title{
Safety of a Combined WB-EMS and High-Protein Diet Intervention in Sarcopenic Obese Elderly Men
}

This article was published in the following Dove Press journal:

Clinical Interventions in Aging

\section{Wolfgang Kemmler (D) Simon von Stengel' Matthias Kohl (D) ${ }^{2}$ Nicolas Rohleder (iD) ${ }^{3}$ Thomas Bertsch ${ }^{4}$ Cornel C Sieber ${ }^{5}$ Ellen Freiberger ${ }^{5}$ Robert Kob (iD ${ }^{5}$}

'Institute of Medical Physics, FriedrichAlexander-Universität ErlangenNürnberg, Erlangen, Germany; ${ }^{2}$ Faculty of Medical and Life Science, University of Furtwangen, Schwenningen, Germany; ${ }^{3}$ Institute of Psychology, FriedrichAlexander-Universität ErlangenNürnberg, Erlangen, Germany; ${ }^{4}$ Institute of Clinical Chemistry, Laboratory Medicine and Transfusion Medicine, General Hospital Nuremberg, Paracelsus Medical University, Nuremberg, Germany; ${ }^{5}$ Institute for Biomedicine of Aging, Friedrich-Alexander-Universität Erlangen-Nürnberg, Nuremberg, Germany
Correspondence: Robert Kob Institute for Biomedicine of Aging, Friedrich-Alexander-Universität ErlangenNürnberg, Kobergerstr. 60, Nuremberg 90408, Germany

Tel +49 9II 5302-96624

Fax +49 9II 5302-96I5।

Email Robert.Kob@fau.de
Purpose: Whole-body electromyostimulation (WB-EMS) especially in combination with a high-protein supplementation has been established as an efficient treatment against sarcopenia. However, there are several case reports of rhabdomyolysis after WB-EMS application. Thus, we asked if this training could potentially lead to deteriorations of the cardiac as well as the renal function.

Materials and Methods: One hundred sarcopenic obese men aged 70 years and older were randomly balanced (1-1-1) and allocated to one of the three study arms. During 16 weeks of intervention, these groups either performed WB-EMS and took a protein supplement (WBEMS\&P), solely received the protein supplement (Protein) or served as control group (CG). WB-EMS consisted of $1.5 \times 20 \mathrm{~min}(85 \mathrm{~Hz}, 350 \mu \mathrm{s}, 4 \mathrm{~s}$ of strain to $4 \mathrm{~s}$ of rest $)$ applied with moderate-to-high intensity while moving. We further generated a daily protein intake of $1.7-1.8 \mathrm{~g} / \mathrm{kg} /$ body mass per day. At baseline and 8-10 days after completion of the intervention, blood was drawn and biomarkers of muscle, cardiac and renal health were assessed. Results: Hereby, we found slight but significant elevations of creatine kinase (CK) levels in the WB-EMS group pointing to minor damages of the skeletal muscle (140 U/1 [81-210], p < $0.001)$. This was accompanied by a significant, low-grade increase of creatine kinase-muscle brain $(\mathrm{CK}-\mathrm{MB}, 0.43 \mathrm{ng} / \mathrm{mL}[-0.29-0.96], \mathrm{p}<0.01)$ and high-sensitivity troponin $\mathrm{T}$ (hsTnT, $0.001 \mathrm{ng} / \mathrm{mL}$. [0.000-0.003], $\mathrm{p}<0.001$ ) but without a higher risk of developing heart failure according to N-terminal prohormone of brain natriuretic peptide (NT-proBNP, $-5.7 \mathrm{pg} / \mathrm{mL}$ [-38.8-24.6], $\mathrm{p}=0.17$ ). Estimated glomerular filtration rate (eGFR) was impaired neither by the high-protein supplementation alone nor in combination with WB-EMS (CG $76.0 \mathrm{~mL} /$ $\mathrm{min} / 1.73 \mathrm{~m}^{2}$ [71.9-82.2] vs Protein $73.2 \mathrm{~mL} / \mathrm{min} / 1.73 \mathrm{~m}^{2}$ [63.0-78.9] vs WB-EMS\&P $74.6 \mathrm{~mL} / \mathrm{min} / 1.73 \mathrm{~m}^{2}$ [62.8-84.1], $\left.\mathrm{p}=0.478\right)$.

Conclusion: In conclusion, even in the vulnerable group of sarcopenic obese seniors, the combination of WB-EMS with a high-protein intake revealed no short-term, negative impact on the eGFR, but potential consequences for the cardiovascular system need to be addressed in future studies.

Keywords: electromyostimulation, high protein, sarcopenic obesity, rhabdomyolysis, CK$\mathrm{MB}$, hsTnT, cystatin C

\section{Introduction}

The loss of muscle mass and function at old age, called sarcopenia, is an important health issue that often leads to loss of independence, falls and fractures, decreased quality of life and finally to a higher overall mortality. ${ }^{1,2}$ Furthermore, sarcopenia could foster further comorbidities like cardiovascular disease, increased inflammation and 
malnutrition. ${ }^{3-5}$ Especially sarcopenic obesity, ie the combination of low muscle mass and obesity was repeatedly been associated with decreased physical function. ${ }^{6-8}$ In this process, an increased fat mass is postulated to exhibit a greater impact on metabolic, muscular as well as cardiovascular health than body weight. ${ }^{9}$ Consistent with that several experts like the American Association of Clinical Endocrinology recommend the use of body fat for the definition of obesity. ${ }^{10,11}$ Physical exercise could at least partly revert these deteriorations. ${ }^{12,13}$ However, most of the affected persons do not fulfil the recommendations for physical activity levels. ${ }^{14}$ Furthermore, a poor health status and fears of falling, pain and joint damage are frequent barriers for conducting conventional types of exercise leading to a downhill spiral of loss of functionality and ability to counteract. $^{15,16}$ Hence, whole-body electromyostimulation (WB-EMS) could be a less demanding, highly individualized and time-efficient option to frequent and intense exercise. ${ }^{17}$ Nevertheless, there are some publications reporting negative health outcomes after the application of WB-EMS. Therefore, there is a need for research on contraindications and possible side effects of WB-EMS. ${ }^{18}$ In particular extreme increases of blood creatine kinase (CK) levels pointing to serious damages of the skeletal muscle were observed. $^{19,20}$ A $10-60 \%$ of pronounced events of rhabdomyolysis of any cause evoke acute kidney damage (AKI) which accounts for approximately $10 \%$ of all AKI. ${ }^{21}$ For WB-EMS there are several investigations on acute WB-EMS effect mainly based on case reports. ${ }^{22-27}$ Indeed, due to its ability to stimulate large muscle areas simultaneously and with regionally dedicated, in excess, supramaximal stimuli, WB-EMS might be the perfect candidate to trigger rhabdomyolysis. In addition, participants could train harder with WB-EMS since the intervention is only limited by the extrinsic stimulus and not by the own ability to provide the necessary power and fitness. These features could easily lead to higher delayed onset muscle soreness and - more important - could have a negative impact on the cardiovascular system. ${ }^{28}$ This would be particularly problematic for sedentary, obese people with underlying cardiac health problems like hypertension or heart failure. Taken together, even though WB-EMS seems to be a highly efficient training method there are only limited investigations regarding its safety especially in vulnerable older participants. Further, apart from one study in younger adults, all studies focus on the acute effect of a single WB-EMS application. ${ }^{27}$

For the preservation of muscle mass, a sufficient provision of protein is a prerequisite. ${ }^{29}$ There is an ongoing debate about the necessary amount, quality and distribution of the daily protein intake because the anabolic effect of the amino acids seems to be blunted at an older age. ${ }^{30,31}$ Consistent with that the German Nutrition Society recommends $1.0 \mathrm{~g}$ protein/ $\mathrm{kg}$ body weight/day for persons above 65 years of age. ${ }^{32}$ Other expert groups even suggest $1.2-1.5$ $\mathrm{g}$ protein $/ \mathrm{kg}$ body weight/day for older adults with underlying sarcopenia or other chronical illnesses. ${ }^{31,33}$ Hence, on the one hand, protein intake over $1.2 \mathrm{~g}$ protein $/ \mathrm{kg}$ body weight/day has been associated with greater fat-free mass compared with a protein intake below 0.8 protein $/ \mathrm{kg}$ body weight/day in older adults in prospective cohort studies. ${ }^{34,35}$ On the other hand, restriction of protein intake helps to delay the need for a renal replacement therapy in patient suffering from chronic kidney disease due to the lower nitrogen load. ${ }^{36}$

In recent publications, we showed that WB-EMS and protein supplementation is efficient to maintain muscle mass and to improve functional parameters in sarcopenic obese women as well as men. ${ }^{37-40}$ In this study, we investigated if there are negative health outcomes for communitydwelling sarcopenic obese men aged 70 years and older after a 16-week intervention with either high-protein supplementation or a combination of high-protein supplementation and WB-EMS. Due to the increased age and number of comorbidities, the presence of metabolic syndrome and the sedentary lifestyle, this group might be particularly vulnerable to the potential complications of this intervention. Therefore, our aim of the presented study was three-folded. We first asked if the WB-EMS leads to a durable increase of the CK levels as a biomarker of damages of the muscle. Second, the impact of the WB-EMS application on biomarkers of cardiovascular health was analyzed. Finally, it was tested if higher doses of protein supplementation alone or superimposed by the WB-EMS induced extensive release of muscular proteins lead to deteriorations of the kidney function.

\section{Materials and Methods}

\section{Trial Design}

The Franconian Sarcopenic Obesity (FranSO) study was a randomized, single-blinded, controlled trial that aimed to determine the effects of two interventions: a) WB-EMS and high-protein supplementation (WB-EMS\&P) and b) isolated protein supplementation (protein); vs an untreated control group (CG) on sarcopenic obesity. Results on effectiveness (ie sarcopenia, obesity, cardiometabolic parameters) of this project were already published. ${ }^{37,38,41}$ The 
numbers of participants in the three parallel study groups were balanced. The trial was planned, implemented and conducted between February and December 2016 by the Institute of Medical Physics (IMP). The IMP was supported by the Institute of Biomedicine of Aging, both part of the University of Erlangen-Nürnberg (FAU), Germany. The University Ethics Committee of the FAU (Ethikantrag 67_15b) approved the FranSO study in April 2015. The study complied with the Declaration of Helsinki's "Ethical Principles for Medical Research Involving Human Subjects." After detailed information, all the study participants gave their written informed consent. The project was registered under ClinicalTrials.gov: NCT2857660.

\section{Participants}

One hundred community-dwelling men 70 years and older and living in the area of Erlangen-Nürnberg, Southern Germany were included in the study. ${ }^{17}$ Furthermore, the participants should have had a skeletal muscle mass index (SMI) $<0.7892$ according to the FNIH criteria ${ }^{19}$ for sarcopenia and $>27 \%$ body fat as recommended by Baumgartner ${ }^{6}$ for obesity. Exclusion criteria were (1) medication (eg, glucocorticoids) or diseases (eg, cushing syndrome) that affected muscle mass or prevented WB-EMS application (eg, cardiac pacemaker), (b) conduction of resistance training ( $>45 \mathrm{~min} /$ week), (c) planned absence for $>2$ weeks during the interventional period, (d) regular "high" alcohol consumption (ie, $>80 \mathrm{~g} /$ day on 5 days/week) and unwillingness to follow the study protocol. All eligible participants were allocated randomly and balanced to the study groups.

\section{Intervention}

The intervention was conducted within an uninterrupted 16-week period between August and December 2016. All three groups received a daily dose of 800 IU Cholecalciferol (Taxofit, Cologne, Germany). Besides this, the CG did not receive any further intervention and was asked to maintain their normal lifestyle.

Both other groups ("WB-EMS\&P" and "protein") were supplemented with a moderate/high daily dose of whey protein (Inkospor Active; Inkospor, Roth, Germany). Based on a 4-day dietary protocol, gathered at the baseline assessment, an individual amount of this protein powder was calculated for each participant to raise the total daily protein intake to $1.7-1.8 \mathrm{~g} / \mathrm{kg}$ body mass/day. One hundred grams of this supplement contained $80 \mathrm{~g}$ (whey) protein with a high L-leucine $(9 \mathrm{~g})$ and essential amino acid (EAA; $57 \mathrm{~g}$ ) component. Every second week, the participants were contacted to control their proper protein (and Vitamin D) supplementation. Otherwise, attendees were engaged to maintain their normal dietary habits including dietary protein intake during the intervention. The 4-day dietary protocol was repeated immediately after the trial and the consumed food was analyzed by a certified nutritionist using the Freiburger Nutrition Protocol (nutri-science, Hausach, Germany).

Additional to the protein powder the WB-EMS group conducted a WB-EMS protocol 1.5 times per week (eg every Tuesday and every second Friday) for 16 weeks. The WB-EMS equipment applied (miha bodytec, Gersthofen, Germany), allowed a simultaneous stimulation of thighs, upper arms, hip/bottom, abdomen, chest, lower back, upper back with an overall area of stimulation of about $2600 \mathrm{~cm} 2$. Thereby, the system allows a selectable and thus dedicated intensity for each of the regions. In the beginning, the timeframe for one session was $14 \mathrm{~min}$ with a progressive increase to $20 \mathrm{~min} / \mathrm{session}$ after 4 weeks. The training was videoguided and any two participants were consistently supervised by one certified instructors. A bipolar electric current with a frequency of $85 \mathrm{~Hz}$ and an impulse width of $350 \mu$ s was applied using an interval approach with $4 \mathrm{~s}$ of electromyostimulation with a direct impulse boost and $4 \mathrm{~s}$ of rest. During the 4 s-impulse phases, different low-intensity movements were conducted in a standing position. Two sets of eight different movements were repeated 6-12 times with an intensity and amplitude that was too low to lead to the training effects of the voluntary exercise alone. This protocol was chosen to overcome the limited impact of static EMS application on neuromuscular coordination and thereby functional outcomes. In order to generate optimum exercise intensity, after 4 weeks of conditioning with lower impulse intensity, the amplitude of the impulses were adapted until the participants rated them as "6-7" (ie "hard+" to "very hard") on the Borg CR10 Scale. This procedure was conducted for each body region in close interaction between participant and instructor. The WB-EMS application was started with the saved initial setting (ie impulse intensity/body region) and the (impulse) intensity was increased slightly every 3 min to achieve the prescribed rate of perceived exertion. The initial setting was evaluated and adjusted at the second session and after 4, 6, 8 and 12 weeks.

\section{Blood Sampling and Intervention}

Blood was drawn on a different date 3 days before the baseline assessment and 8-10 days following completion of the intervention. After an overnight fast, blood was 
consistently sampled between 7:00 and 9:00 in the morning in a sitting position from an antecubital vein. Past clotting for at least half an hour, serum samples were centrifuged for 20 min at 3000 RPM and the supernatant was stored frozen at $-80^{\circ} \mathrm{C}$. All measurements were performed at the Institute of Clinical Chemistry, Laboratory Medicine and Transfusion Medicine, General Hospital Nuremberg, Paracelsus Medical University, Nuremberg, Germany with a Cobas 8000 with reagents from the manufacturer (Roche Diagnostics GmbH, Mannheim, Germany). The creatinine test was based on the Jaffé method and was IDMS-traceable while the Tina-quant Cystatin $\mathrm{C}$ was a particle-enhanced immunoturbidimetric assay. The estimated glomerular filtration rate (eGFR) for creatinine was calculated by the CKD-EPI formula: for creatinine $\leq 0.9 \mathrm{mg} / \mathrm{dl}$ eGFR $=141$ $\times(\text { concentration of creatinine } / 0.9)^{-0.411} \times(0.993)^{\text {Age }}$ and for creatinine $>0.9 \mathrm{mg} / \mathrm{dl}$ eGFR $=141 \times$ (concentration of creatinine/0.9 $)^{-1.209} \times(0.993)^{\text {Age.42 }}$ The estimated glomerular filtration rate for cystatin $\mathrm{C}$ (eGFR_cysC) was calculated by the CKD-EPI formula: for cystatin $\mathrm{C} \leq 0.8 \mathrm{mg} / 1$ eGFR_cysC $=133 \times(\text { concentration of cystatin } \mathrm{C} / 0.8)^{-0.499}$ $\times(0.996)^{\text {Age }}$ and for cystatin $\mathrm{C}>0.8 \mathrm{mg} / \mathrm{l}$ eGFR_cys $\mathrm{C}=133 \times(\text { concentration of cystatin } \mathrm{C} / 0.8)^{-1.328}$ $\times(0.996)^{\text {Age. } 43}$ For analysis of high-sensitivity C-reactive protein (hsCRP), we used the cardiac $\mathrm{C}$ reactive protein (Latex) high sensitive assay (Roche Diagnostics $\mathrm{GmbH}$, Mannheim, Germany) measured with the cobas 8000 with the limit of detection of $0.15 \mathrm{mg} / \mathrm{l}$. The samples were processed according to the accredited clinical standard operating principles of the laboratory in batch to avoid alterations due to differences in charges or daily conditions. High-sensitivity interleukin 6 (hsIL 6) was measured using a commercially available ELISA kit (HS600B; R\&D Systems, Inc., Minneapolis, USA) according to the manufactures' instructions.

\section{Sample Size}

The sample size calculation of the FranSO study was based on the primary study endpoint "changes of Sarcopenia Z-Score". In a recent publication, however with a female cohort, we found a change of the Sarcopenia Z-Score of 1.3 \pm 1.2 (index). ${ }^{37}$ Applying a T-Score-based sample size analysis and using a more conservative assumption of $1.0 \pm 1.4$ (index), 31 participants per group were necessary to generate $80 \%$ power and a two-sided significance level of $5 \%$.

\section{Randomization Procedures}

Hundred-one participants were randomly assigned to three study arms (a) WB-EMS\&P, (b) Protein and (c) CG by an allocation rate of 1:1:1 (Figure 1). For the group allocation, participants draw lots by themselves. Each lot was put in small opaque plastic containers ("kinder egg", Ferrero, Italy) and drawn from one bowl. Thus, allocation concealment was realized since neither participants nor researchers knew the allocation beforehand. Next, the primary investigator (AW) enrolled participants and instructed them in detail about their group status and corresponding dos and don'ts.

\section{Blinding}

We conducted a semi blinded approach that focusses on research assistants/outcome assessors. Since the WB-EMS training could not be mimicked for the participants and trainers we focus on blinding of outcome assessors. Outcome assessors did not know the participants' group status (WB-EMS\&P, Protein or CG) and were not allowed to ask. This should prevent an unconscious bias of the outcome testing and analysis by the investigator.

\section{Statistical Analysis}

Statistical analyses were performed with R statistics software ( $\mathrm{R}$ Development Core Team Vienna, Austria) in combination with multiple imputation by Amelia II and SPSS Version 24 (IBM SPSS Statistics, Chicago, IL, USA). Descriptive statistics were used for the characterization of participants. After checking for normality with the Shapiro-Wilk test, data is either presented as mean standard deviation (SD) (normally distributed) or median with $25 \%$ and $75 \%$ quartile. Group differences in continuous data were tested using a one-way ANOVA or the Kruskal-Wallis test (as appropriate). If this test was significant, pairwise comparisons with Bonferroni adjustment were carried out.

Changes in the biomarkers of muscle/cardiovascular health, inflammation, total protein, albumin and cystatin $\mathrm{C}$ between baseline and follow-up measurements were analyzed using an ITT approach. The ITT analysis included all the randomized participants independent of their compliance or whether they were lost to follow-up. For multiple imputation, the full data set was used, with imputation being repeated 100 times. Overimputation diagnostic plots of Amelia II were utilized to confirm that the multiple imputation 


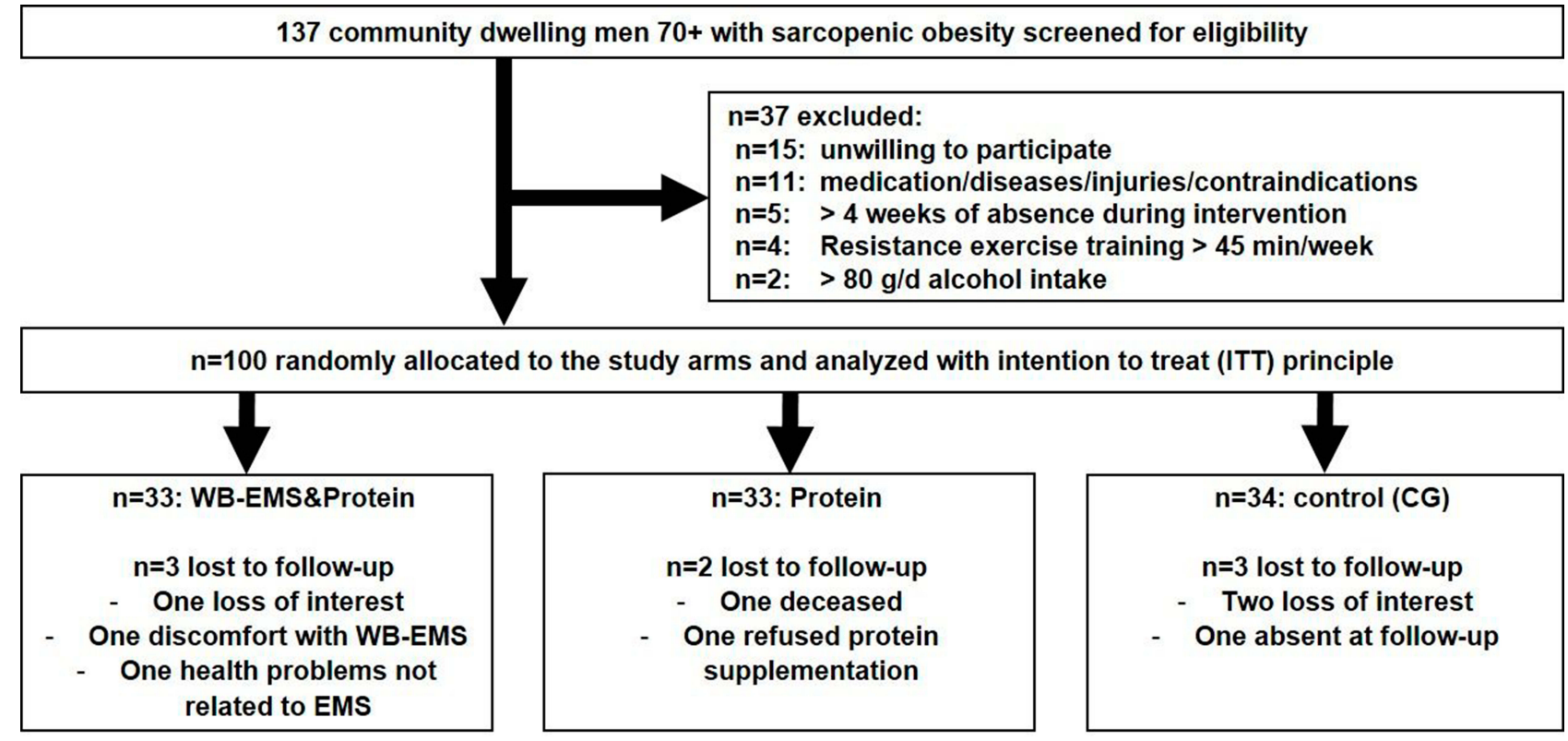

Figure I Diagram of participants flow through the study.

worked well in all cases. Based on a statistically and graphically checked normal distribution, the primary and secondary outcomes presented here were analyzed by dependent $t$ tests for within-group changes. To identify group differences, pairwise $t$ test comparisons with pooled SD were applied. The $\mathrm{p}$ values obtained in the pairwise comparisons were adjusted for multiple testing by the method of Holm. In order to detect difference in nominal scaled (baseline) data, $\chi 2$ tests were applied. All tests were two-tailed; significance was accepted at $\mathrm{p}<0.05$ or adjusted $\mathrm{p}<0.05$, respectively.

\section{Results}

\section{Baseline Characteristics}

The baseline characteristics according to the study arms are listed in Table 1. There were no significant differences detectable between the groups. Most of the participants had a daily protein intake of over $1.0 \mathrm{~g} / \mathrm{kg}$ body weight/ day as suggested for this age group. ${ }^{33}$ However, a larger proportion of the protein group did not fulfill this recommendation at baseline. This variation was not significant in

Table I Characteristics of the Participants of the FranSO Study at Baseline

\begin{tabular}{|c|c|c|c|c|}
\hline Variable & WB-EMS\&P & Protein & $\mathbf{C G}$ & $P$ value \\
\hline Age [years] & 77.1 [75.6-78.7] & 78.1 [76.3-80.0] & $76.9[75.2-78.7]$ & 0.571 \\
\hline Lean body mass $[\mathrm{kg}]$ & 51.8 [49.9-53.6] & $52.1[50.3-54.1]$ & $52.6[50.5-54.8]$ & 0.805 \\
\hline $\mathrm{SMI}\left[\mathrm{kg} /\left(\mathrm{kg} / \mathrm{m}^{2}\right)\right]^{\mathrm{a}}$ & $0.709[0.695-0.734]$ & $0.703[0.681-0.723]$ & $0.710[0.687-0.732]$ & 0.730 \\
\hline Total body fat [\%] & $31.6[30.5-32.9]$ & $31.4[30.4-32.4]$ & $31.4[30.3-32.5]$ & 0.967 \\
\hline Number of diseases [n] & $2.71[2.38-3.05]$ & $2.78[2.36-3.16]$ & $2.56[2.16-2.96]$ & 0.584 \\
\hline Protein intake $[\mathrm{g} / \mathrm{kg} / \mathrm{day}]$ & 1.17 [1.06-1.29] & $0.98[0.76-1.22]$ & $1.21[1.06-1.37]$ & 0.352 \\
\hline Sodium $[\mathrm{mmol} / \mathrm{l}]$ & | 46.3 [|44.9-|49.7] & $145.5[|43.8-| 48.6]$ & |45.6 [|44.8-|47.7] & 0.372 \\
\hline Potassium [mmol/l] & $4.78[4.29-4.93]$ & $4.50[4.25-4.79]$ & $4.57[4.38-4.93]$ & 0.357 \\
\hline Calcium $[\mathrm{mmol} / \mathrm{l}]$ & $2.39[2.36-2.45]$ & $2.37[2.32-2.42]$ & $2.41[2.34-2.46]$ & 0.144 \\
\hline Magnesium $[\mathrm{mmol} / \mathrm{l}]$ & $0.88[0.86-0.95]$ & $0.85[0.80-0.89]$ & $0.84[0.82-0.89]$ & 0.085 \\
\hline Chloride $[\mathrm{mmol} / \mathrm{l}]$ & $106.8[105.3-108.3]$ & $106.2[104.1-109.0]$ & 105.9 [104.3-107.9] & 0.557 \\
\hline Phosphorus [mmol/l] & $1.00[0.91-1.10]$ & $1.05[1.00-1.12]$ & $\mathrm{I} .02$ [0.95-I.II] & 0.472 \\
\hline Uric acid [mg/dl] & $6.4[5.3-7.0]$ & $6.6[5.7-7.8]$ & $6.2[5.8-6.7]$ & 0.384 \\
\hline Creatinine $[\mathrm{mg} / \mathrm{dl}]$ & $\mathrm{I} .02[0.97-\mathrm{I} .18]$ & $1.05[0.96-1.17]$ & $0.98[0.86-1.07]$ & 0.139 \\
\hline Urea [mg/dl] & 33.8 [29.4-4I.I] & 39.8 [34.5-43.5] & 34.0 [25.3-42.2] & 0.079 \\
\hline
\end{tabular}

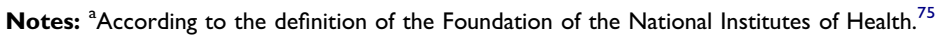

Abbreviation: SMI, skeletal muscle index. 
comparison to the other study arms. The number of diseases was comparable between the groups. Hypertension (67\%) was the most frequent self-reported disorder, followed by arthrosis (30\%) and back pain (23\%) while no participant stated a renal disease. Taken together, this collective had elevated barriers for conducting "normal" exercise. Consistent with that, most of the participants exhibited serum levels of creatinine and urea that were below the upper threshold of the reference values provided by the manufacturer of the assay $(1.20 \mathrm{mg} / \mathrm{dl}$ and $48.5 \mathrm{mg} / \mathrm{dl}$, respectively). None of the electrolytes showed any significant differences between the groups at follow-up.

\section{Adherence to the Protocol}

Figure 1 gives the participant flow through the trial. Adherence rate for WB-EMS was $91 \pm 7 \%$. Impulse intensity as assessed by Borg CR10 and requested after 4, 6, 8 and 16 weeks of WB-EMS averaged $6.8 \pm 0.3$ (ie very hard) and was thus within our prescription of RPE 6-7.

We observed a slightly lower protein powder intake than prescribed; however, due to a slightly increased dietary protein intake, total protein intake averaged around $1.78 \pm 0.09 \mathrm{~g} / \mathrm{kg} / \mathrm{d}$ in the WB-EMS\&P and Protein group, respectively. With respect to safety aspects, no injuries or relevant adverse effects were observed or reported by the participants during the interventional period.

\section{Biomarkers of Muscular and Cardiovascular Health}

At baseline, the levels of CK $(p=0.737)$, creatine kinase muscle brain (CKMB; $\mathrm{p}=0.194)$ and $\mathrm{N}$-terminal prohormone of brain natriuretic peptide (NT-proBNP, $\mathrm{p}=0.948$ ), as biomarkers of muscular and cardiovascular health, were comparable between the groups (Table 2). However, highsensitivity troponin (hsTnT) was significantly lower in the WB-EMS\&P than in the control group $(\mathrm{p}=0.02)$. It has to be noted that the levels of hsTnT in our whole study population were near or even exceeding the concentration threshold of $0.014 \mathrm{ng} / \mathrm{mL}$ that is described as the 99th percentile reference limit of a healthy control population. ${ }^{44}$ This could be due to the increased age of our participants as already described by other groups. ${ }^{45,46}$ Hence, this slight elevation is not likely to be clinically relevant.

During the intervention, only eight participants dropped out ( 3 from CG, 2 from protein and 3 from WB-EMS\&P group, respectively) (Figure 1). Of these, one reported discomfort with the WB-EMS, and one other of this study branch discontinued due to health problems. Thus, nearly all participants could finish this intervention without developing obvious health problems. However, there were several investigations lined out that WB-EMS could lead to elevated serum levels of creatine kinase that might point to negative health outcomes. ${ }^{20}$ Because of this, we analyzed the CK concentrations after completion of the intervention (Figure 2). In the ITT analysis, only the WB-EMS group exhibited a significant increase of the CK levels from baseline to follow-up $(\mathrm{p}<0.001)$ that leads to a higher concentration compared to the protein $(\mathrm{p}=0.008)$ but not to the control group ( $\mathrm{p}=0.096$ ). It has to be noted that even after this elevation most of the WB-EMS exhibited CK values under or only slightly above the consensus value of $190 \mathrm{U} / \mathrm{l}^{47}$

Not only Rhabdomyolysis but also cardiac damage could result in $\mathrm{CK}$ concentration increases. ${ }^{48}$ Especially, in our obese collective that did not exercise a sportive overload could have a negative impact on the heart. Thus, we also measured CKMB and hsTnT as more specific biomarkers of an acute heart muscle damage. While the ITT analysis revealed a significant increase of CKMB only in the WB-EMS\&P group $(\mathrm{p}<0.01)$ no significant difference in comparison to the other study branches $(\mathrm{p}=0.105$ for the absolute value at follow-up, $\mathrm{p}=0.089$ for change) could be shown. Furthermore, the majority of participants exhibited values below the cut-off value of the assay $(6.22 \mathrm{ng} / \mathrm{mL})$. The same holds true for the results of the hsTnT measurement which were also significantly increased in the WBEMS\&P group after the intervention $(\mathrm{p}<0.0001)$. Nevertheless, hsTnT levels were also higher compared to the control group $(p=0.34)$ and the difference to the protein group had a borderline significance after adjustment according to Holm $(p=0.067)$. However, the changes were slightly and similar to the range of the $\mathrm{CG}$ at baseline. Taken together, the WB-EMS\&P intervention led to minor but significant increases not only of the $\mathrm{CK}$, as a marker of muscle health, but also of the cardiac markers CK-MB and hsTnT. These biomarkers are more sensitive to acute damages. Thus, we measured NT-proBNP which has a good prognostic value for incident heart failure. ${ }^{49}$ Hereby, no significant changes within as well as between the intervention branches could be detected ( $p=0.600$ for the absolute value at follow-up, $p=0.537$ for change). Furthermore, no differences in any group or intervention were seen in the inflammatory biomarkers hsCRP and hsIL6 (CRP: $\mathrm{p}=0.878$ for the absolute value at follow-up, $\mathrm{p}=0.442$ for change; hsIL $6: \mathrm{p}=0.676$ for the absolute 
Table 2 Biomarkers of Muscular and Cardiovascular Health

\begin{tabular}{|c|c|c|c|c|}
\hline Variable & WB-EMS\&P & Protein & CG & $P$ value \\
\hline \multicolumn{5}{|l|}{ CK [U/I] } \\
\hline Baseline & $86[77-126]$ & $98[73-136]$ & 98 [74-146] & 0.737 \\
\hline Follow-up & $\mid 40[8|-2| 0]$ & $91[74-124]$ & $109[66-174]$ & 0.029 \\
\hline Change & $31.0[-5.8-88.3]^{\#, \mathrm{a}}$ & $-9.5[-43.3-7.0]^{\text {n.s., a }}$ & $3.0[-36.0-21.0]^{\text {n.s. }}$ & 0.009 \\
\hline \multicolumn{5}{|c|}{ CKMB [ng/mL] } \\
\hline Baseline & $2.76[1.96-3.33]$ & $2.82[1.94-3.85]$ & 3.11 [2.22-4.49] & 0.194 \\
\hline Follow-up & $2.97[2.50-4.15]$ & $2.93[2.09-4.04]$ & $4.14[2.47-5.15]$ & 0.105 \\
\hline Change & $0.43[-0.29-0.96]^{*}$ & $0.01[-0.56-0.47]^{\text {n.s. }}$ & $0.26[-.38-1.07]^{\text {n.s. }}$ & 0.089 \\
\hline \multicolumn{5}{|c|}{$\mathrm{hsTnT}[\mathrm{ng} / \mathrm{mL}]$} \\
\hline Baseline & $0.011[0.008-0.014]^{\mathrm{b}}$ & $0.011[0.009-0.014]$ & $0.015[0.010-0.019]^{\mathrm{b}}$ & 0.020 \\
\hline Follow-up & $0.012[0.010-0.019]$ & $0.012[0.009-0.014]$ & $0.014[0.011-0.017]$ & 0.308 \\
\hline Change & $0.001[0.000-0.003]^{\#, c}$ & $0.000[-0.00 \mathrm{I}-0.00 \mathrm{I}]^{\text {n.s. }}$ & $0.000[-0.002-0.002]^{\text {n.s., c }}$ & 0.008 \\
\hline \multicolumn{5}{|c|}{ NT-proBNP [pg/mL] } \\
\hline Baseline & 128 [77-252] & $125[76-219]$ & 129 [94-277] & 0.948 \\
\hline Follow-up & 112 [7|-195] & $\mid 35[78-2||]$ & $|2|$ [7|-274] & 0.600 \\
\hline Change & $-5.7[-38.8-24.6]$ & $1.9[-28.9-36.1]$ & $-6.3[-35.6-13.5]$ & 0.537 \\
\hline \multicolumn{5}{|l|}{ hsCRP [mg/l] } \\
\hline Baseline & $0.94[0.60-2.21]$ & $1.19[0.70-2.06]$ & I.47 [0.59-3.07] & 0.462 \\
\hline Follow-up & $1.02[0.66-3.06]$ & $1.28[0.76-2.84]$ & $1.54[0.67-3.44]$ & 0.878 \\
\hline Change & $0.14[-0.02-0.60]$ & $0.18[-0.44-0.73]$ & $0.00[-0.70-0.73]$ & 0.442 \\
\hline \multicolumn{5}{|l|}{ hsIL 6 [ng/l] } \\
\hline Baseline & $1.27[0.85-2.16]$ & $1.17[0.82-1.76]$ & $1.20[0.94-1.74]$ & 0.748 \\
\hline Follow-up & $1.18[0.91-1.91]$ & $0.93[0.71-1.91]$ & $1.27[0.84-1.96]$ & 0.676 \\
\hline Change & $-0.02[-0.43-0.44]$ & $-0.08[-0.35-0.48]$ & $0.20[-0.40-0.71]$ & 0.434 \\
\hline
\end{tabular}

Notes: ${ }^{a}$ significant difference between protein and WB-EMS\&P group $P=.008$; ${ }^{b}$ significant difference between CG and WB-EMS\&P group $P=.033$; ${ }^{c}$ significant difference between CG and WB-EMS\&P group $p=.034$, *significant intra-group difference $(p<.01)$ between baseline and follow-up, ${ }^{\#}$ significant intra-group difference ( $P<.001$ ) between baseline and follow-up, Data are presented as median and [25-75\% quartile range].

Abbreviations: WB-EMS\&P, whole-body electromyostimulation and protein supplementation; CG, control group; CK, creatine kinase; CK-MB, creatine kinase-muscle brain; hsTnT, high-sensitivity troponin T; NT-proBNP, N-terminal prohormone of brain natriuretic peptide; hsCRP, high-sensitivity C-reactive protein; hsIL 6, high-sensitivity interleukin 6; n.s., not significant.

value at follow-up, $\mathrm{p}=0.434$ for change). Therefore, we postulate that the WB-EMS application had a short-term effect on the cardiovascular system without inducing longterm impairments.

\section{Biomarkers of Protein Metabolism and Renal Health}

In the next step, we evaluated the impact of the protein supplementation. Even though the participants did not consume the whole-prescribed amount of whey powder, ${ }^{37}$ the relative protein intake per body weight was highly significant increased within the WB-EMS\&P as well as the protein group $(\mathrm{p}<0.001$ for both; Table 3$)$. This lead to a significantly higher consumption of protein compared to the control group $(\mathrm{p}<0.001)$. However, neither serum total protein nor albumin got elevated due to the intervention. In comparison to the control group, the change of albumin was even significantly lower change in the WB-EMS\&P group compared to the control group $(p=0.23)$. Nevertheless, this deviation was due to an increase in a very small increase in the CG, while the other groups showed constant levels.

Rhabdomyolysis could lead to disturbance of the kidneys. ${ }^{22}$ Especially, if a high-protein diet is consumed this could lead to a further deterioration of the renal function ${ }^{36}$ For this reason, we measured serum levels of creatinine and urea as biomarkers of renal clearance and nitrogen balance (Figure 3). Both factors were unaffected by the high-protein supplementation and the WB-EMS treatment. However, both biomarkers could be influenced by diet and by muscle mass. ${ }^{50}$ To avoid a masking effect of our intervention, we also measured cystatin $\mathrm{C}$ which is independent of muscle mass and nutrition. $^{51,52}$ While creatinine and urea were within the 

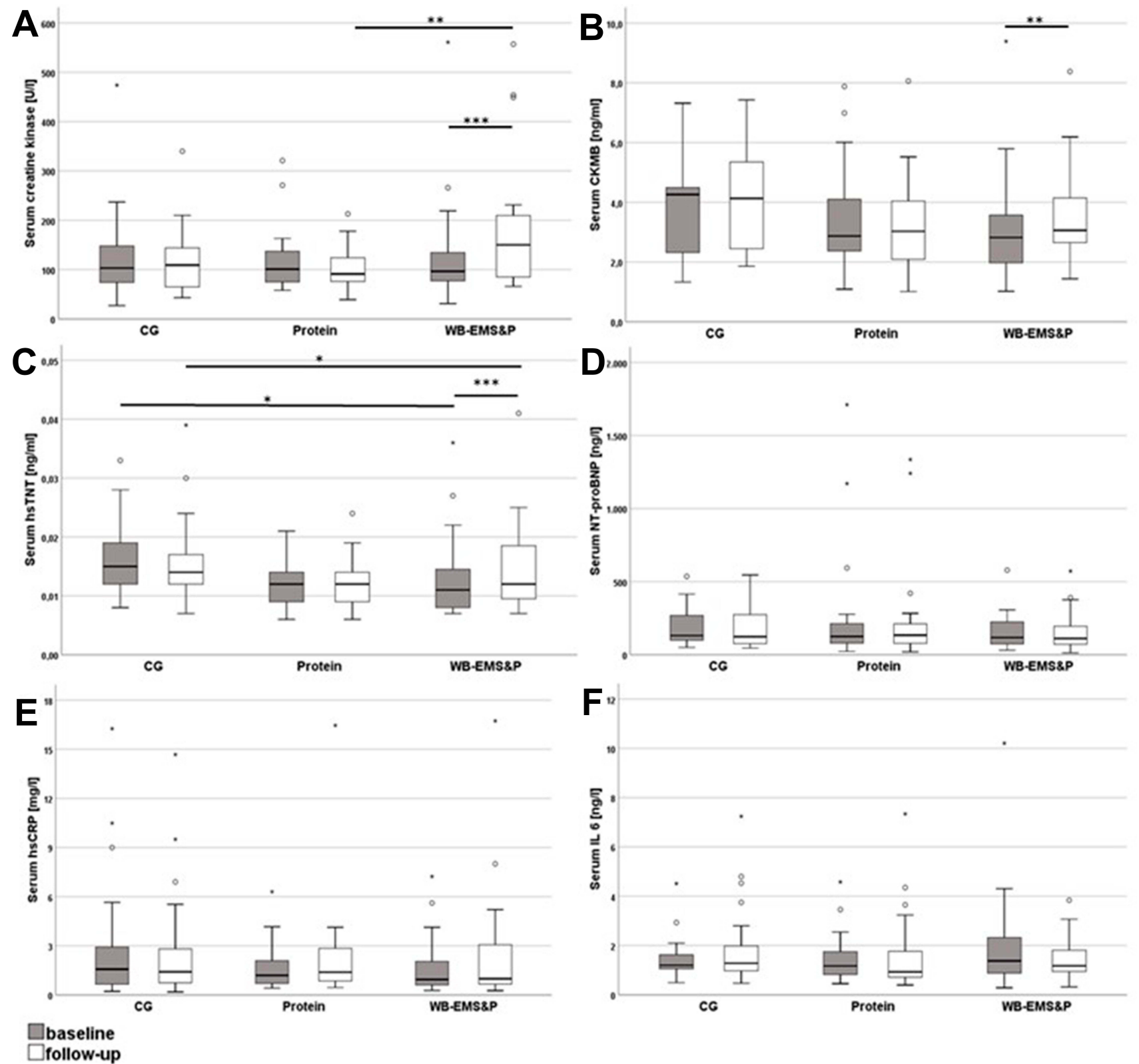

Figure 2 Biomarkers of muscular and cardiovascular health of the intervention groups at baseline and follow-up with clinical reference range (dotted lines). (A) creatine kinase, (B) CKMB, (C) hsTnT, (D) NT-proBNP, (E) hsCRP and (F) hslL 6. The boxes represent interquartile ranges with the bold horizontal lines denoting the median. The whiskers show the highest and lowest values within the I.5-fold interquartile range. The circles represent outliers and asterisks represent extreme outliers. Significant changes within a group and between groups at the same time point are marked with black lines. ${ }^{*} p<0.05$; ${ }^{* *} p<0.0$; ${ }^{* * *} p<0.001$.

reference values, cystatin $\mathrm{C}$ was slightly elevated in all groups at baseline $\left(1.02 \mathrm{mg} / 1\right.$ for people over 50 years of age $\left.{ }^{53}\right)$. This points to a beginning decline of renal filtration especially in the background of the decreased muscle mass of this study population. Still, cystatin $\mathrm{C}$ was not elevated during the intervention neither in protein nor in the WB-EMS\&P group. There was even a trend to decreasing cystatin $\mathrm{C}$ levels in comparison to the $C G$ with borderline significance $(p=0.064)$. The estimated glomerular filtration rate (eGFR) represents a better estimate of the filtration performance of the liver since it also includes age, gender and race. ${ }^{42,43}$ Therefore, we also calculated the eGFR for creatinine as well as for cystatin C. In line with the results of the analysis of creatinine and cystatin $\mathrm{C}$ no significant group differences could be detected. Of note, the protein and the control group exhibited significant changes in the creatinine-based calculation of the eGFR between baseline and follow-up (both $\mathrm{p}<0.001$ ) in the ITT analysis. However, the absolute differences of these eGFR variations 
Table 3 Biomarkers of Protein Metabolism and Renal Health

\begin{tabular}{|c|c|c|c|c|}
\hline Variable & WB-EMS\&P & Protein & CG & $P$ value \\
\hline \multicolumn{5}{|l|}{ Protein intake [g/kg body weight/day] } \\
\hline Baseline & $1.17[0.90-1.47]$ & $0.98[0.76-1.22]$ & $1.12[0.87-1.50]$ & 0.054 \\
\hline Follow-up & $1.76[1.63-1.82]$ & $1.70[1.58-1.81]$ & $1.20[1.04-1.36]$ & $<.001$ \\
\hline Change & $0.47[0.29-0.73]^{\S, a}$ & $0.64[0.45-0.83]^{\S ., ~ a ~}$ & $0.11[-0.16-0.22]^{\text {n.s, a }}$ & $<.001$ \\
\hline \multicolumn{5}{|l|}{ Albumin $[\mathrm{g} / \mathrm{dl}]$} \\
\hline Baseline & $4.5[4.4-4.6]$ & $4.5[4.3-4.7]$ & $4.5[4.4-4.6]$ & 0.598 \\
\hline Follow-up & $4.5[4.4-4.6]$ & $4.5[4.4-4.7]$ & $4.6[4.5-4.7]$ & 0.303 \\
\hline Change & $0.0[-0.2-0.1]^{\text {n.s., b }}$ & $0.1[-0.2-0.2]^{\text {n.s. }}$ & $0.1[0.0-0.3]^{\text {n.s., b }}$ & 0.028 \\
\hline \multicolumn{5}{|l|}{ Total protein $[\mathrm{g} / \mathrm{dl}]$} \\
\hline Baseline & $7.0[6.8-7.2]$ & $7.0[6.9-7.3]$ & $7.1[6.8-7.3]$ & 0.888 \\
\hline Follow-up & $7.0[6.9-7.3]$ & $7.1[7.0-7.3]$ & $7.2[7.0-7.4]$ & 0.071 \\
\hline Change & $0.1[-0.2-0.3]^{\text {n.s. }}$ & $0.2[-0.1-0.3]^{\text {n.s. }}$ & $0.2[0.0-0.4]^{*}$ & 0.219 \\
\hline \multicolumn{5}{|l|}{ Creatinine $[\mathrm{mg} / \mathrm{dl}]$} \\
\hline Baseline & $1.02[0.96-1.19]$ & $1.05[0.96-1.17]$ & $0.98[0.86-1.08]$ & 0.139 \\
\hline Follow-up & $0.95[0.85-1.11]$ & $0.98[0.91-1.08]$ & $0.96[0.87-1.03]$ & 0.612 \\
\hline Change & $-0.08[-0.13--0.02]$ & $-0.06[-0.11--0.02]$ & $-0.02[-0.08-0.02]$ & 0.053 \\
\hline \multicolumn{5}{|l|}{ Urea $[\mathrm{mg} / \mathrm{dl}]$} \\
\hline Baseline & $33.8[29.3-41.3]$ & $39.8[34.5-43.5]$ & $34.0[25.2-42.7]$ & 0.079 \\
\hline Follow-up & $39.1[33.4-48.3]$ & $41.3[36.0-45.7]$ & $37.8[29.1-46.0]$ & 0.542 \\
\hline Change & $4.7[0.6-10.6]$ & $0.8[-4.2-7.4]$ & $0.4[-4.0-7.1]$ & 0.179 \\
\hline \multicolumn{5}{|l|}{ Cystatin C [mg/l] } \\
\hline Baseline & $1.15[1.05-1.25]$ & $1.16[1.04-1.28]$ & $1.12[1.02-1.32]$ & 0.749 \\
\hline Follow-up & $1.11[1.00-1.22]$ & $1.12[1.03-1.35]$ & $1.17[1.08-1.33]$ & 0.356 \\
\hline Change & $-0.04[-0.08-0.01]$ & $-0.04[-0.08-0.04]$ & $0.01[-0.04-0.07]$ & 0.064 \\
\hline \multicolumn{5}{|l|}{ eGFR_creatinine $\left[\mathrm{mL} / \mathrm{min} / \mathrm{I} .73 \mathrm{~m}^{2}\right]$} \\
\hline Baseline & $69.2[58.4-76.2]$ & $67.3[59.8-76.7]$ & $74.8[65.7-84.6]$ & 0.106 \\
\hline Follow-up & $74.6[62.8-84.1]$ & $73.2[63.0-78.9]$ & $76.0[71.9-82.2]$ & 0.478 \\
\hline Change & $4.59[0.99-10.47]$ & $2.97[1.48-6.59]^{\#}$ & $0.87[-1.46-5.81]^{\#}$ & 0.303 \\
\hline \multicolumn{5}{|l|}{ eGFR_cystatin C $\left[\mathrm{mL} / \mathrm{min} / 1.73 \mathrm{~m}^{2}\right]$} \\
\hline Baseline & $60.6[54.5-68.1]$ & $58.3[50.5-69.4]$ & $62.8[50.4-69.6]$ & 0.713 \\
\hline Follow-up & $63.2[56.2-73.2]$ & $62.5[49.1-70.6]$ & $59.3[50.3-66.1]$ & 0.413 \\
\hline Change & $2.94[-0.98-6.20]$ & $2.21[-3.11-5.75]$ & $-0.40[-5.78-2.80]$ & 0.663 \\
\hline
\end{tabular}

Notes: ${ }^{a}$ Significant difference between control and both intervention groups $\left(p=<.001\right.$ for both) ${ }^{b}$ significant difference between CG and WB-EMS\&P group ( $P=.023$ ), *significant intra-group difference $(\mathrm{P}<.0 \mathrm{l})$ between baseline and follow-up, ${ }^{*}$ significant intra-group difference $(\mathrm{p}<.00 \mathrm{I})$ between baseline and follow-up, ${ }^{\S}$ significant intragroup difference $(p<.0 \mathrm{I})$ between baseline and follow-up, Data are presented as median and [25-75\% quartile range].

Abbreviations: WB-EMS\&P, whole-body electromyostimulation and protein supplementation; CG, control group; n.s., not significant; eGFR, estimated glomerular filtration rate.

were low and are not reflected in the cystatin C-based eGFR. Therefore, the clinical relevance of this finding seems to be questionable.

\section{Discussion}

Despite recent recommendations on safety and effectiveness in WB-EMS application, ${ }^{54}$ higher $\mathrm{CK}$ values after WB-EMS were frequently reported. Mostly these changes were only measured within $24 \mathrm{~h}$ after the training. ${ }^{28,55} \mathrm{In}$ this study, we could show that WB-EMS training might lead to persistent increased levels of CK even 8-10 days after completion of the intervention compared to control as well as the protein supplementation group. It has to be noted, that most of the $\mathrm{CK}$ values remained under or only slightly above the clinical threshold of $190 \mathrm{U} / 1 .{ }^{47}$ Additionally, other forms of physical training also increase CK levels without exhibiting negative consequences. ${ }^{19,28}$ Therefore, a clinical relevance of this deviation does not seem to be likely. In other investigations, the repetitive application of WB-EMS led to a blunted elevation of the 


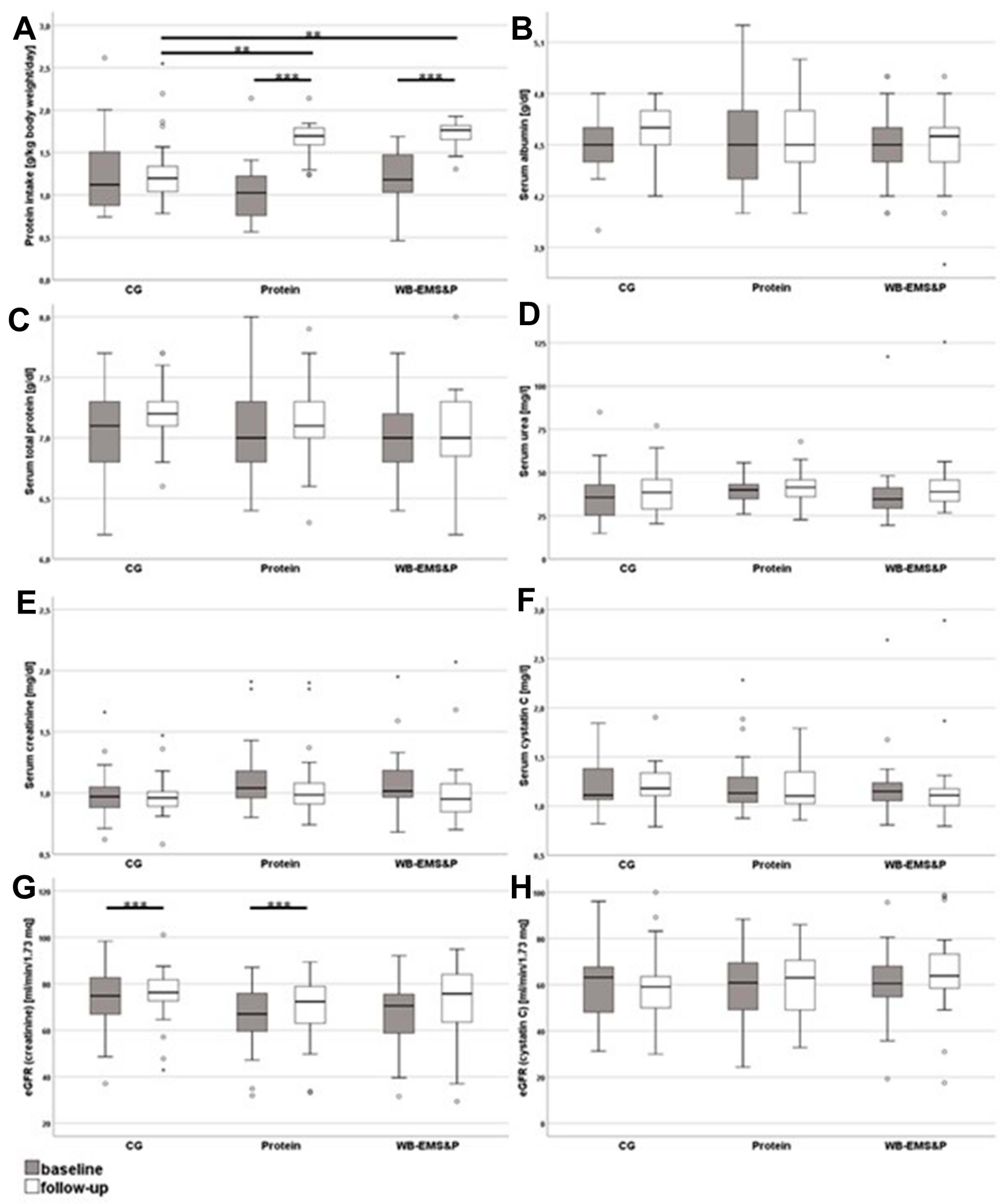

Figure 3 Biomarkers of protein metabolism and renal health of the intervention groups at baseline and follow-up. (A) daily protein intake of the participants, (B) albumin, (C) total protein, (D) urea, (E) creatinine, (F) cystatin C, (G) creatinine-based eGFR and (H) cystatin C-based eGFR. The boxes represent interquartile ranges with the bold horizontal lines denoting the median. The whiskers show the highest and lowest values within the 1.5 -fold interquartile range. The circles represent outliers and asterisks represent extreme outliers. Significant changes within a group and between groups at the same time point are marked with black lines. $*^{*} p<0.01 ;{ }^{* * *} p<0.001$. 
CK after the session. ${ }^{19,28}$ Thus, we speculate that our participants presumably had also higher increases after the first training sessions and this effect was gradually faded out during the course of the study. Nevertheless, this could not be validated since we have only taken blood samples before and after the end of the intervention. Particularly due to its ability to stimulate all main muscle groups (up to $2800 \mathrm{~cm}^{2}$ ) simultaneous, but with dedicated, in excess supramaximal intensity WB-EMS might be the "perfect" candidate to trigger rhabdomyolysis and corresponding CK-levels. ${ }^{56}$ Extreme elevations of $\mathrm{CK}$ and myoglobin are reached when EMS is superimposed with additional high-intensity physical training compared to EMS or training alone. ${ }^{55}$ Additionally, these elevations seem to be more pronounced when WB-EMS is not only applied with a (too) high impulse intensity but also during the initial training sessions. ${ }^{19}$ In our current study, we overcome these problems by combining the WB-EMSprotocol just with light movements and by a progressive enhancement of the intensity amplitude after 4 weeks of conditioning. We postulate that this procedure prevented serious muscular damages and in consequence helped to gain a high attendance rate in this trial. Consistent with that only one participant withdraw due to discomfort with the WB-EMS. In future studies, it has to be analyzed if this adapted protocol also leads to smaller swings in the levels of muscular health biomarkers by using a more comprehensive measurement kinetic.

It has to be noted that $\mathrm{CK}$ is expressed in several tissues and therefore elevated CK levels could also stem from damages of heart cells. ${ }^{48}$ Even though CK is widely used as a marker for rhabdomyolysis due to its high diagnostic and prognostic performance as well as its high availability in clinical laboratories and low costs. ${ }^{48}$ In order to overcome this issue, we extended our analysis and included heart-specific biomarkers. To our knowledge, this was the first study investigating the impact of WBEMS on CK-MB, hsTnT and NT-proBNP. We found slight elevations of the CK-MB in the WB-EMS group pointing to a potential damage of the heart muscle. It has to be pointed out that the skeletal muscle also expresses CK-MB but in small quantities. ${ }^{57}$ Therefore, it could not be ruled out that the observed CK-MB elevation was due to deteriorations of the skeletal muscle. In consequence, we also measured the highly heart-specific hsTnT. ${ }^{49}$ This troponin isoform also increased significantly within the WB-EMS from baseline to follow-up. This is in line with findings from other studies reporting elevated hsTnT after exercise training. ${ }^{58}$ It was postulated that this change is not caused by a necrotic damage to heart cells but rather by a physiological release of the cytosolic troponin from the cells. ${ }^{59}$ Consistent with that, there are no studies showing the typical biphasic pattern of hsTnT release after an acute coronary syndrome is also present after extensive sports. This would mean an initial release approximately $2 \mathrm{~h}$ after the event followed by a later release due to degradation of the contractile apparatus. ${ }^{60}$ Moreover, the increase of hsTnT was even more pronounced in apparently healthy subjects while those with signs of myocardial ischemia revealed a blunted response. ${ }^{59}$ The changes within our collective were only discrete and could have been evoked by chance since the control group exhibited similar hsTnT levels at baseline as the WB-EMS group at follow-up. Older persons often show concentrations of hsTnT above the 99th percentile threshold that could not be linked to an acute coronary syndrome. ${ }^{45}$ With a specificity of only about $28 \%$ in patients 75 years and older, the simple measurement of hsTnT at one time point is not sufficient to diagnose an acute heart damage. ${ }^{46}$ For CK-MB as well as for hsTnT we analyzed the steady state after the completion of the WB-EMS intervention. To get better insights into the physiological adaptions to the electrical stimulation, future studies need to perform a measurement of the kinetics of these cardiac biomarkers during and soon after the treatment. Of note, NT-proBNP did not reveal any changes due to the intervention. Since this marker is a better predictor of future events of heart failure than the other analyzed parameters, ${ }^{49,61}$ we postulate that the WB-EMS training did not have a permanent negative effect on the cardiovascular health. This is in line with other studies that applied WB-EMS in the even more vulnerable group of heart failure patients. These groups also did not report negative health outcomes due to the intervention. ${ }^{62-64}$ For a more comprehensive view, we also measured hsCRP and hsIL 6 as markers of ongoing inflammation. Both parameters did not reveal any influence of the intervention on the induction of inflammatory responses. Reduction of adipose tissue and building up of muscle due to exercise could lead to decreases of markers of inflammation. ${ }^{9}$ On the other hand, damages to the muscle could have led to the upregulation of inflammation. ${ }^{65}$ Additionally, the muscle itself produces large quantities of hsIL 6 after extensive training. ${ }^{66}$ The overlapping of all these physiological responses could have masked the direct effect of the WB-EMS on the 
analyzed biomarkers of inflammation. A recent metaanalysis found only modest effects of resistance training on hsCRP and hsIL 6 levels that were only present in trials with a high number of exercises, high weekly frequency and long duration. ${ }^{67}$ Thus, our study might potentially not provide the power to detect these beneficial adaptions; however, we could exclude an acute inflammation due to damages of the skeletal muscle.

Rhabdomyolysis has been linked to acute kidney damage. ${ }^{21}$ This could be further reinforced by the consumption of a high-protein diet. ${ }^{36}$ In this study, the participant of the protein as well as the WB-EMS\&P group increased their protein intake to approximately $1.7 \mathrm{~g}$ protein $/ \mathrm{kg}$ body weight/day highly significant compared to the control group. Of note, this intake was higher than most of the common recommendations. ${ }^{32,33}$ Therefore, we asked if this intervention could also have a negative impact on renal function. In a recent publication, we showed that this consumption of whey protein significantly improved skeletal muscle index, lowered total body fat and waist circumference but did not change handgrip strength. ${ }^{37,41}$ However, we did not find an effect of the protein supplementation neither on improving levels of total serum protein nor on serum albumin. This could be explained by the fact that the participants were not mal-nourished and exhibited albumin $(3.5-5.0 \mathrm{~g} / \mathrm{dl})$ and total protein $(6.4-8.3 \mathrm{~g} / \mathrm{dl})$ values that were within the reference ranges. ${ }^{68}$ Thus, the additional amino acids were stored within the muscle while there was no physiological need to increase the protein concentrations in the blood. ${ }^{37}$ Creatinine and urea also showed no accumulation due to the high-protein diet. Interestingly, creatinine even revealed a borderline significant reduction between the WB-EMS\&P and the control group. Consistent with this result, a recent meta-analysis including 11 studies with 362 chronic kidney disease patients (stage 3-4) showed a modest effect of exercise on the estimated glomerular filtration rate. ${ }^{69}$ However, creatinine as well as urea is highly interrelated with muscle mass and dietary behavior and have only a limited capability to detect damages of the kidney at an early stage. ${ }^{50,70}$ Therefore, we also analyzed cystatin $\mathrm{C}$ that revealed a slightly decreased renal function in most of the participants. As for creatinine, cystatin $C$ levels also were reduced in the WB-EMS\&P and protein group at follow-up compared to the control group with a borderline significance. However, these effects were rather small and do not seem to have a clinical relevance. Taken together, neither the protein supplementation alone nor in combination with the WB-EMS training deteriorate the renal function in our study sample. Consistent with that creatinine clearance and general kidney function were not impaired after a 1-year lifestyle intervention including a diet with higher protein intake in a recently published study. ${ }^{71}$ Furthermore, a systematic review Van Elswyk et al reported that higher protein intake $(\geq 20 \%$ but $<35 \%$ of energy or $\geq 10 \%$ higher than a comparison intake) did not impair renal function in healthy adults and higher protein intake was even associated with an increase in glomerular filtration rate. ${ }^{72}$ However, it has to be pointed out that our study could only analyze the short-term effects of the protein supplementation. Longer periods of excessive protein consumption with increased glomerular filtration rate are likely to stress the kidneys and lead to a decreased renal function. ${ }^{36}$

Some features and limitations of the present study have to be considered. At first, we applied a rather conventional WB-EMS protocol. After increasing the duration to $20 \mathrm{~min}$, we focused exclusively on adequate (impulse) intensity. Thus, the main difference between FranSO and commercially practiced WB-EMS protocols is the slightly higher training frequency of 1.5 vs 1 session per week. Second, the protein supplementation intervention was not blinded because the control group did not receive a CHO placebo to ensure "isocaloric conditions". Since protein induces thermogenesis and decreases energy efficiency supplying the same amount of $\mathrm{CHO}$ and proteins might even have generated a significant bias. ${ }^{73}$ Indeed, in contrast to FranSO, none of the corresponding studies reported significant reductions in body fat after protein supplementation. The acquisition of the total protein intake was not based on an objective measurement of markers of protein metabolism but on self-reported, dietary analysis only. Although this method was considered reliable, assessing protein markers such as urine urea or urine nitrogen as well would have provided deeper insight into (changes of) protein metabolism of the participants. Third, there is no consensus definition of sarcopenic obesity today. The prevalence of sarcopenic men could range from $4.4 \%$ to $84.0 \%$ depending on the definition applied. ${ }^{74}$ Therefore, there might be a selection and definition bias in this study limiting the comparability with similar trials in this field. Fourth, the participants were recruited by public announcements and came to the intervention independently. This could have led to a selection bias with an overrepresentation of fitter, healthier and more motivated attendees. However, the participants exhibited reduced muscle mass and several comorbidities what underlines that they experienced negative consequences of sarcopenic obesity and were at the need of 
a counteracting intervention. Fifth, one may consider the lack of an isolated WB-EMS group as a further study limitation. However, the main aim of this setting was to determine the combined effect of two parameters probably related to negative effects on kidney function. Sixth, we only analyzed blood parameters at baseline and 8-10 days after the end of the 16-week intervention. Most of the biomarkers' levels could have been normalized within this period after the end of the treatment. Thus, we could not exclude more pronounced effects directly after a WB-EMS session eg as already described for the CK concentrations. $^{20}$ Furthermore, we did not conduct direct measurements of the cardiac functionality eg by using ultrasound echocardiography. The analysis of the renal function was focused on the filtration of creatinine and cystatin $\mathrm{C}$ but we could not exclude that other kidney functions were affected by the high-protein intake leading to proteinuria/albuminuria, calciuria, and acidosis. However, persistent deteriorations of the glomerular filtration rate as well as an increasing probability for heart failure would have been detected with this protocol. Future studies should analyze the impact of the wholebody electromyostimulation, especially on the cardiac markers with a kinetic after a single session as well as in the course of the whole intervention. This would help to exclude an acute negative impact of the training on the cardiovascular system and to optimize the tolerability of the WB-EMS protocols.

\section{Conclusion}

A WB-EMS intervention in sarcopenic obese older was associated with slight elevations of some biomarkers of muscular damage without signs of acute harms of the participants. Neither supplementation of high-protein doses alone nor in combination with the WB-EMS training led to detectable deteriorations of indices of the glomerular filtration rate. Therefore, short-term interventions of WB-EMS in combination with protein supplementation seem to be an efficient and safe intervention against sarcopenia and sarcopenic obesity even in a vulnerable group. The elevations of hsTnT and CK-MB need to be investigated in further studies.

\section{Data Sharing Statement}

The data that support the findings of this study are available from the corresponding author, upon reasonable request.

\section{Acknowledgments}

The authors would like to express their thanks for the support from the non-profit organization and university health sport club "Netzwerk Knochengesundheit e.V.", which co-funded the project.

\section{Disclosure}

The authors report no conflicts of interest in this work.

\section{References}

1. Cruz-Jentoft AJ, Bahat G, Bauer J, et al. Sarcopenia: revised European consensus on definition and diagnosis. Age Ageing. 2019;48(1):16-31. doi:10.1093/ageing/afy169

2. Schaap LA, van Schoor NM, Lips P, Visser M. Associations of sarcopenia definitions, and their components, with the incidence of recurrent falling and fractures: the longitudinal aging study amsterdam. J Gerontol a Biol Sci Med Sci. 2018;73(9):1199-1204. doi:10.1093/gerona/glx245

3. Perna S, Peroni G, Anna FM, et al. Sarcopenia and sarcopenic obesity in comparison: prevalence, metabolic profile, and key differences. A cross-sectional study in Italian hospitalized elderly. Aging Clin Exp Res. 2017:1-10. doi:10.1007/s40520-016-0701-8

4. Newman AB, Simonsick EM, Naydeck BL, et al. Association of long-distance corridor walk performance with mortality, cardiovascular disease, mobility limitation, and disability. JAMA. 2006;295 (17):2018-2026. doi:10.1001/jama.295.17.2018

5. Kim J-H, Cho JJ, Park YS. Relationship between sarcopenic obesity and cardiovascular disease risk as estimated by the framingham risk score. J Korean Med Sci. 2015;30(3):264-271. doi:10.3346/ jkms.2015.30.3.264

6. Baumgartner RN, Wayne SJ, Waters DL, Janssen I, Gallagher D, Morley JE. Sarcopenic obesity predicts instrumental activities of daily living disability in the elderly. Obes Res. 2004;12(12):1995-2004. doi:10.1038/oby.2004.250

7. Auyeung TW, Lee JSW, Leung J, Kwok T, Woo J. Adiposity to muscle ratio predicts incident physical limitation in a cohort of 3153 older adults -an alternative measurement of sarcopenia and sarcopenic obesity. AGE. 2013;35(4):1377-1385. doi:10.1007/s11357-012-9423-9

8. Jung S, Yabushita N, Kim M, et al. Obesity and muscle weakness as risk factors for mobility limitation in community-dwelling older Japanese women: a two-year follow-up investigation. $J$ Nutr Health Aging. 2016;20(1):28-34. doi:10.1007/s12603-016-0672-7

9. Batsis JA, Villareal DT. Sarcopenic obesity in older adults: aetiology, epidemiology and treatment strategies. Nat Rev Endocrinol. 2018;14 (9):513-537. doi:10.1038/s41574-018-0062-9

10. Garvey WT, Mechanick JI, Brett EM, et al. American association of clinical endocrinologists And American college of endocrinology comprehensive clinical practice guidelines for medical care of patients with obesity. Endocr Pract. 2016;22(Suppl 3):1-203. doi:10.4158/EP161365.GL

11. Bouchard DR, Dionne IJ, Brochu M. Sarcopenic/obesity and physical capacity in older men and women: data from the Nutrition as a determinant of successful aging (NuAge) - the quebec longitudinal study. Obesity. 2009;17(11):2082-2088. doi:10.1038/oby.2009.109

12. Cesari M, Vellas B, Hsu F-C, et al. A physical activity intervention to treat the frailty syndrome in older persons-results from the LIFE-P STUDY. J Gerontol a Biol Sci Med Sci. 2015;70(2):216-222. doi:10.1093/gerona/glu099

13. Landi F, Cesari M, Calvani R, et al. The "Sarcopenia and Physical fRailty IN older people: multi-componenT Treatment strategies" (SPRINTT) randomized controlled trial: design and methods. Aging Clin Exp Res. 2017;29(1):89-100. doi:10.1007/s40520-016-0715-2 
14. Carlson SA, Fulton JE, Schoenborn CA, Loustalot F. Trend and prevalence estimates based on the 2008 physical activity guidelines for Americans. Am J Prev Med. 2010;39(4):305-313. doi:10.1016/j. amepre.2010.06.006

15. Moschny A, Platen P, Klaaßen-Mielke R, Trampisch U, Hinrichs T. Barriers to physical activity in older adults in Germany: a cross-sectional study. Int J Behav Nutr Phys Activity. 2011;8(1):121. doi:10.1186/1479-5868-8-121

16. Simmonds BAJ, Hannam KJ, Fox KR, Tobias JH. An exploration of barriers and facilitators to older adults' participation in higher impact physical activity and bone health: a qualitative study. Osteoporos Int. 2016;27(3):979-987. doi:10.1007/s00198-015-3376-7

17. Kemmler W, von Stengel S. Whole-body electromyostimulation as a means to impact muscle mass and abdominal body fat in lean, sedentary, older female adults: subanalysis of the TEST-III trial. Clin Interv Aging. 2013;8:1353-1364. doi:10.2147/CIA.S52337

18. Stöllberger C, Finsterer J. Side effects of and contraindications for whole-body electro-myo-stimulation: a viewpoint. BMJ Open Sport Exerc Med. 2019;5(1):e000619. doi:10.1136/bmjsem-2019-000619

19. Kemmler W, Teschler M, Bebenek M, von Stengel S. Hohe Kreatinkinase-Werte nach exzessiver Ganzkörper-Elektromyost imulation: gesundheitliche Relevanz und Entwicklung im Trainingsverlauf. Wien Med Wochenschr. 2015;165(21):427-435. doi:10.1007/s10354-015-0394-1

20. Stöllberger C, Finsterer J. Side effects of whole-body electro-myostimulation. Wien Med Wochenschr. 2019;169(7):173-180. doi:10.10 07/s10354-018-0655-x

21. Mai H, Zhao Y, Salerno S, Li Y, Yang L, Fu P. Rhabdomyolysisinduced acute kidney injury in a patient with undifferentiated connective tissue disease: a case report and literature review rhabdomyolysis-induced AKI in a patient with UCTD. Medicine. 2019;98(30):e16492. doi:10.1097/MD.0000000000016492

22. Peng F, Lin X, Sun L, et al. Exertional rhabdomyolysis in a 21 -year-old healthy man resulting from lower extremity training: a case report. Medicine. 2019;98(28):e16244. doi:10.1097/MD.0000000000016244

23. Hong JY, Oh JH, Shin J. Rhabdomyolysis caused by knee push-ups with whole body electromyostimulation. Br J Hosp Med. 2016;77 (9):542-543. doi:10.12968/hmed.2016.77.9.542

24. Guarascio P, Lusi E, Soccorsi F. Electronic muscular stimulators: a novel unsuspected cause of rhabdomyolysis. $\mathrm{Br} J$ Sports Med. 2004;38(4):505. doi:10.1136/bjsm.2003.008540

25. Guillén Astete CA, Zegarra Mondragón S, Medina Quiñones C. Rhabdomyolysis secondary to physical activity and simultaneous electrostimulation. A case report. Rheumatol Clin. 2015;11 (4):262-263. doi:10.1016/j.reumae.2015.03.010

26. Kästner A, Braun M, Meyer T. Two cases of rhabdomyolysis after training with electromyostimulation by 2 young male professional soccer players. Clin J Sport Med. 2015;25(6):e71-e73. doi:10.1097/ JSM.0000000000000153

27. Teschler M, Weissenfels A, Fröhlich M, Kohl M, Bebenek M, Kemmler W. (Very) high creatine kinase (CK) levels after whole-body electromyostimulation. Are there implications for health? Int J Clin Exp Med. 2016;9(11):10.

28. Wirtz N, Wahl P, Kleinöder H, Wechsler K, Achtzehn S, Mester J. Acute metabolic, hormonal, and psychological responses to strength training with superimposed EMS at the beginning and the end of a 6 week training period. J Musculoskelet Neuronal Interact. 2015;15 (4):325-332.

29. Martone AM, Lattanzio F, Abbatecola AM, et al. Treating sarcopenia in older and oldest old. Curr Pharm Des. 2015;21(13):1715-1722. doi:10.2174/1381612821666150130122032

30. Gingrich A, Spiegel A, Kob R, et al. Amount, distribution, and quality of protein intake are not associated with muscle mass, strength, and power in healthy older adults without functional limitations - an enable study. Nutrients. 2017;9(12):1358. doi:10.3390/ nu9121358
31. Bauer J, Biolo G, Cederholm T, et al. Evidence-based recommendations for optimal dietary protein intake in older people: a position paper from the PROT-AGE study group. J Am Med Dir Assoc. 2013;14(8):542-559. doi:10.1016/j.jamda.2013.05.021

32. Richter M, Baerlocher K, Bauer JM, et al. Revised reference values for the intake of protein. ANM. 2019;74(3):242-250. doi:10.1159/ 000499374

33. Deutz NEP, Bauer JM, Barazzoni R, et al. Protein intake and exercise for optimal muscle function with aging: recommendations from the ESPEN Expert Group. Clin Nutr. 2014;33(6):929-936. doi:10.1016/j. clnu.2014.04.007

34. Meng X, Zhu K, Devine A, Kerr DA, Binns CW, Prince RL. A 5-Year Cohort Study of the Effects of High Protein Intake on Lean Mass and BMC in Elderly Postmenopausal Women. J Bone Mineral Res. 2009;24(11):1827-1834. doi:10.1359/jbmr.090513

35. Houston DK, Nicklas BJ, Ding J, et al. Dietary protein intake is associated with lean mass change in older, community-dwelling adults: the health, aging, and body composition (Health $\mathrm{ABC}$ ) study. Am J Clin Nutr. 2008;87(1):150-155. doi:10.1093/ajcn/87.1.150

36. Fois A, Chatrenet A, Cataldo E, et al. Moderate protein restriction in advanced CKD: a feasible option in an elderly, high-comorbidity population. A stepwise multiple-choice system approach. Nutrients. 2019;11(1):36. doi:10.3390/nu11010036

37. Kemmler W, Weissenfels A, Teschler M, et al. Whole-body electromyostimulation and protein supplementation favorably affect sarcopenic obesity in community-dwelling older men at risk: the randomized controlled FranSO study. Clin Interv Aging. 2017;12:1503-1513. doi:10.2147/CIA.S137987

38. Kemmler W, Grimm A, Bebenek M, Kohl M, von Stengel S. Effects of combined whole-body electromyostimulation and protein supplementation on local and overall muscle/fat distribution in older men with sarcopenic obesity: the randomized controlled franconia sarcopenic obesity (FranSO) study. Calcif Tissue Int. 2018;103 (3):266-277. doi:10.1007/s00223-018-0424-2

39. Kemmler W, Teschler M, Weissenfels A, et al. Whole-body electromyostimulation to fight sarcopenic obesity in community-dwelling older women at risk. Results of the randomized controlled FORMOsA-sarcopenic obesity study. Osteoporos Int. 2016;27 (11):3261-3270. doi:10.1007/s00198-016-3662-z

40. von Stengel S, Bebenek M, Engelke K, Kemmler W. Whole-body electromyostimulation to fight osteopenia in elderly females: the randomized controlled training and electrostimulation trial (TEST-III). J Osteoporos. 2015;2015:1-7. doi:10.1155/2015/643520

41. Kemmler W, Kohl M, Freiberger E, Sieber C, von Stengel S. Effect of whole-body electromyostimulation and/or protein supplementation on obesity and cardiometabolic risk in older men with sarcopenic obesity: the randomized controlled FranSO trial. BMC Geriatr. 2018;18. doi:10.1186/s12877-018-0759-6

42. Levey AS, Stevens LA, Schmid CH, et al. A new equation to estimate glomerular filtration rate. Ann Intern Med. 2009;150 (9):604. doi:10.7326/0003-4819-150-9-200905050-00006

43. Inker LA, Schmid CH, Tighiouart H, et al. Estimating glomerular filtration rate from serum creatinine and cystatin C. $N$ Engl J Med. 2012;367(1):20-29. doi:10.1056/NEJMoa1114248

44. Saenger AK, Beyrau R, Braun S, et al. Multicenter analytical evaluation of a high-sensitivity troponin $\mathrm{T}$ assay. Clin Chimica Acta. 2011;412(9):748-754. doi:10.1016/j.cca.2010.12.034

45. Normann J, Mueller M, Biener M, Vafaie M, Katus HA, Giannitsis E. Effect of older age on diagnostic and prognostic performance of high-sensitivity troponin $\mathrm{T}$ in patients presenting to an emergency department. Am Heart J. 2012;164(5):698-705.e4. doi:10.1016/j. ahj.2012.08.003

46. Riedlinger D, Möckel M, Müller C, et al. High-sensitivity cardiac troponin $\mathrm{T}$ for diagnosis of NSTEMI in the elderly emergency department patient: a clinical cohort study. Biomarkers. 2018;23 (6):551-557. doi:10.1080/1354750X.2018.1460763 
47. Thomas L, Müller M, Schumann G, et al. Consensus of DGKL and VDGH for interim reference intervals on enzymes in serum Konsensus von DGKL und VDGH zu vorläufigen Referenzbereichen für Serumenzyme. LaboratoriumsMedizin. 2005;29(5):301-308. doi:10. 1515/JLM.2005.041

48. Lippi G, Schena F, Ceriotti F. Diagnostic biomarkers of muscle injury and exertional rhabdomyolysis. Clin Chem Lab Med. 2018;57 (2):175-182. doi:10.1515/cclm-2018-0656

49. Welsh P, Papacosta O, Ramsay S, et al. High-sensitivity troponin $\mathrm{t}$ and incident heart failure in older men: british regional heart study. J Card Fail. 2019;25(4):230-237. doi:10.1016/j.cardfail.2018.08.002

50. Lamb EJ, Tomson CR, Roderick PJ. Estimating kidney function in adults using formulae. Ann Clin Biochem. 2005;42(5):321-345. doi: $10.1258 / 0004563054889936$

51. Dharnidharka VR, Kwon C, Stevens G. Serum cystatin C is superior to serum creatinine as a marker of kidney function: a meta-analysis. Am J Kidney Dis. 2002;40(2):221-226. doi:10.1053/ajkd.2002.34487

52. Fliser D, Ritz E. Serum cystatin C concentration as a marker of renal dysfunction in the elderly. Am J Kidney Dis. 2001;37(1):79-83. doi:10.1053/ajkd.2001.20628

53. Finney H, Newman DJ, Price CP. Adult reference ranges for serum cystatin C, creatinine and predicted creatinine clearance. Ann Clin Biochem. 2000;37(1):49-59. doi:10.1258/0004563001901524

54. Kemmler W, Froehlich M, von Stengel S, Kleinöder H. Whole-body electromyostimulation - the need for common sense! Rationale and guideline for a safe and effective training. Dtsch Z Sportmed. 2016;2016(09):218-221. doi:10.5960/dzsm.2016.246

55. Wahl P, Hein M, Achtzehn S, Bloch W, Mester J. Acute effects of superimposed electromyostimulation during cycling on myokines and markers of muscle damage. J Musculoskelet Neuronal Interact. 2015;15(1):53-59.

56. Koch AJ, Pereira R, Machado M. The creatine kinase response to resistance exercise. J Musculoskelet Neuronal Interact. 2014;14(1):68-77.

57. Carmona G, Roca E, Guerrero M, et al. Fibre-type-specific and mitochondrial biomarkers of muscle damage after mountain races. Int J Sports Med. 2019;40(4):253-262. doi:10.1055/a-0808-4692

58. Sedaghat-Hamedani F, Kayvanpour E, Frankenstein L, et al. Biomarker changes after strenuous exercise can mimic pulmonary embolism and cardiac injury - a metaanalysis of 45 studies. Clin Chem. 2015;61(10):1246-1255. doi:10.1373/clinchem.2015.240796

59. Saad YME, Idris H, Shugman IM, et al. Evaluation of serial high sensitivity troponin $\mathrm{t}$ levels in individuals without overt coronary heart disease following exercise stress testing. Heart Lung Circ. 2017;26(7):660-666. doi:10.1016/j.hlc.2016.11.004

60. Shave R, Baggish A, George K, et al. Exercise-induced cardiac troponin elevation: evidence, mechanisms, and implications. $\mathrm{J} \mathrm{Am}$ Coll Cardiol. 2010;56(3):169-176. doi:10.1016/j.jacc.2010.03.037

61. Linssen GCM, Bakker SJL, Voors AA, et al. N-terminal pro-B-type natriuretic peptide is an independent predictor of cardiovascular morbidity and mortality in the general population. Eur Heart J. 2010;31(1):120-127. doi:10.1093/eurheartj/ehp420

62. Fritzsche D, Fruend A, Schenk S, et al. Elektromyostimulation (EMS) bei kardiologischen Patienten. Herz. 2010;35(1):34-40. doi:10.1007/s00059-010-3268-8
63. Iliou MC, Vergès-Patois $\mathrm{B}$, Pavy $\mathrm{B}$, et al. Effects of combined exercise training and electromyostimulation treatments in chronic heart failure: a prospective multicentre study. Eur J Prev Cardiol. 2017;24(12):1274-1282. doi:10.1177/2047487317712601

64. van Buuren F, Mellwig KP, Prinz C, et al. Electrical myostimulation improves left ventricular function and peak oxygen consumption in patients with chronic heart failure: results from the exEMS study comparing different stimulation strategies. Clin Res Cardiol. 2013;102(7):523-534. doi:10.1007/s00392-013-0562-5

65. Teschler M, Mooren FC. (Whole-Body) Electromyostimulation, Muscle Damage, and Immune System: A Mini Review. Front Physiol. 2019;10. doi:10.3389/fphys.2019.01461

66. Pedersen BK, Febbraio MA. Muscle as an endocrine organ: focus on muscle-derived interleukin-6. Physiol Rev. 2008;88(4):1379-1406. doi:10.1152/physrev.90100.2007

67. Sardeli AV, Tomeleri CM, Cyrino ES, Fernhall B, Cavaglieri CR, Chacon-Mikahil MPT. Effect of resistance training on inflammatory markers of older adults: A meta-analysis. Exp Gerontol. 2018;111:188-196. doi:10.1016/j.exger.2018.07.021

68. Coley-Grant D, Herbert M, Cornes MP, Barlow IM, Ford C, Gama R. The impact of change in albumin assay on reference intervals, prevalence of 'hypoalbuminaemia' and albumin prescriptions. Ann Clin Biochem. 2016;53(1):112-116. doi:10.1177/0004563215599560

69. Vanden Wyngaert K, Van Craenenbroeck AH, Van Biesen W, et al. The effects of aerobic exercise on eGFR, blood pressure and VO2peak in patients with chronic kidney disease stages 3-4: a systematic review and meta-analysis. PLoS One. 2018;13(9): e0203662. doi:10.1371/journal.pone.0203662

70. Murty MSN, Sharma UK, Pandey VB, Kankare SB. Serum cystatin C as a marker of renal function in detection of early acute kidney injury. Indian J Nephrol. 2013;23(3):180-183. doi:10.4103/0971-4065.111840

71. Møller G, Rikardt Andersen J, Ritz C, et al. Higher protein intake is not associated with decreased kidney function in pre-diabetic older adults following a one-year intervention-a preview sub-study. Nutrients. 2018;10(1):54. doi:10.3390/nu10010054

72. Van Elswyk ME, Weatherford CA, McNeill SH. A systematic review of renal health in healthy individuals associated with protein intake above the us recommended daily allowance in randomized controlled trials and observational studies. Adv Nutr. 2018;9(4):404-418. doi:10.1093/advances/nmy026

73. Melzer K. Carbohydrate and fat utilization during rest and physical activity. Eur e J Clin Nutr Metab. 2011;6(2):e45-e52. doi:10.1016/j. eclnm.2011.01.005

74. Batsis JA, Barre LK, Mackenzie TA, Pratt SI, Lopez-Jimenez F, Bartels SJ. Variation in the prevalence of sarcopenia and sarcopenic obesity in older adults associated with different research definitions: dual-Energy X-Ray absorptiometry data from the national health and nutrition examination survey 1999-2004. J Am Geriatr Soc. 2013;61 (6):974-980. doi:10.1111/jgs.12260

75. Studenski SA, Peters KW, Alley DE, et al. The FNIH sarcopenia project: rationale, study description, conference recommendations, and final estimates. J Gerontol a Biol Sci Med Sci. 2014;69 (5):547-558. doi:10.1093/gerona/glu010
Clinical Interventions in Aging

\section{Publish your work in this journal}

Clinical Interventions in Aging is an international, peer-reviewed journal focusing on evidence-based reports on the value or lack thereof of treatments intended to prevent or delay the onset of maladaptive correlates of aging in human beings. This journal is indexed on PubMed Central, MedLine, CAS, Scopus and the Elsevier
Bibliographic databases. The manuscript management system is completely online and includes a very quick and fair peer-review system, which is all easy to use. Visit http://www.dovepress.com/ testimonials.php to read real quotes from published authors. 